\title{
SWEET CHERRY SKIN COLOUR MEASUREMENT AS AN NON-DESTRUCTIVE INDICATOR OF FRUIT MATURITY
}

\author{
- Research paper - \\ Piotr CHEŁPIŃSKI*, Ireneusz OCHMIAN*1, Paweł FORCZMAŃSKI** \\ * Department of Horticulture, Faculty of Environmental Management and Agriculture, West \\ Pomeranian University of Technology Szczecin, Slowackiego 17 Street, 71-434 Szczecin, Poland; \\ Piotr Chetpiński; piotr.chelpinski@zut.edu.pl \\ Ireneusz Ochmian; ORCID 0000-0002-3606-1927, \\ ** Chair of Multimedia Systems, Faculty of Computer Science and Information Technology, West \\ Pomeranian University of Technology Szczecin, 49 Żotmierska Street, 71-210 Szczecin Poland \\ ORCID0000-0002-3618-9146,pforczmanski@wi.zut.edu.pl
}

\begin{abstract}
Colour measurement is one of the methods used to evaluate food quality. Aim of completed research was the evaluation of a fast and non-destructive method which consisted of assessing colour changes. It was used to determine the ripeness of cherries during their harvest. Additionally, the most significant parameter determining fruit ripeness was identified. Colour measurements of the Burlat cherry on the PHL A rootstocks were supposed to provide standards for practical evaluation of fruit ripeness of this species at an orchard. During the research, the measurements concerned the internal quality of the cherry fruit (firmness, extract content) and the force required to tear off the stem, depending on the size of the fruit. The extract appeared to be the most important indicator to be used for the determination of an optimum harvesting period. It was most prominently correlated with the cherry's colour. Changes in the skin colour were the most reflected by the value of the parameter CIE $a^{*}$. The coordinates CIE $\mathrm{L}^{*}$ and $\mathrm{b}^{*}$ are also important for the determination of fruit quality. Burlat cherries achieve their optimum harvesting ripeness if the coordinate $\mathrm{a}^{*}$ is within the range 30.0 to 0.0 , the coordinate $b^{*}$ within 10.0 to 0.0 and the coordinate $\mathrm{L}^{*}$ within 30.0 to 20.0 , which corresponds to the extract value of $12-20 \%$.
\end{abstract}

Keywords: CIEL*a*b*, dimensionality reduction, classification, harvesting date, fruit quality, Prunus avium L.

\section{INTRODUCTION}

Consumers expect to have constant access to fresh high-quality fruits. Such fruits should be firm and coloured, but they should also be characterised by high sugar content and appropriate levels of acids and pro-health components (Crisosto et al., 2003; Serrano et al., 2009). These are the properties that determine the selection of the appropriate harvest time, which is usually defined with the use of destructive methods for fruits. These methods are time-consuming and usually employed under laboratory conditions (Pappas et al., 2011; Escribano et al., 2017; Li et al., 2018). However, the storage industry is looking for solutions, which will allow it to assess the quality of fruits in a quick, economical and non-destructive method, preferably during the sorting process. Standard

Received: 19.10.2019.

Accepted in revised form: 4.12 .2019 destructive procedures allow only for the evaluation of control batches (Paz et al.,2008). What is also sought are quick and relatively accurate methods for evaluating the quality of fruits under field conditions (Nicolai et al., 2005; Overbeck et al., 2017). However, it demands the determination of appropriate measuring methods and indicators, which would allow for evaluating parameters of individual species, and sometimes even cultivars (Pappas et al., 2011; Zanella et al., 2013). There are various methods which can be used for that purpose, such as spectrophotometry, time-resolved reflectance spectroscopy, hyperspectral backscattering imaging or chlorophyll fluorescence (Zude et al., 2009; Zerbini et al., 2003; Peng and $\mathrm{Lu}, 2008$; Bauriegel et al., 2011).

They are all based on the use of light exposure of a given object: the light is absorbed, radiated, reflected or dispersed by the sample. Nowadays, the main focus is drawn to optical methods, including spectroscopy in a visible range and nearinfrared spectroscopy (Zude et al., 2011; Mireei et

${ }^{1}$ Corresponding author. E-Mail address: Ireneusz.Ochmian@zut.edu.pl 
al., 2010; Rutkowski et al., 2008). The Normalised Difference Vegetation Index and Normalised Anthocyanin Index are used to evaluate the quality of fruits of different species (Rutkowski et al., 2008; Seifert et al., 2015). There is a high correlation between firmness and content of acids. Those methods are not always well-defined and need to be elaborated with the use of calibration models (Zerbini, 2006; Seifert et al., 2015). An analysis of the fruit surface colour is also used. Colour is a good indicator that describes the physiological changes in fruit (Antal et. al., 2013). Color changes are also used to determine the quality of food products during their processing (Yusufe et al., 2017). In many plants, a change in the colour of the fruit is associated with the degradation of the chorophyll and the synthesis of other pigments. There is also dominance of other pigments formed during fruit growth (Ferrer et al., 2005). During growth of fruits, biochemical changes occur, which influence their physical parameters (Łysiak, 2011; Ochmian et. al., 2016). A description of those changes may be useful to determine the best time for harvest, which will make it possible to extend the storage period
(Lysiak et al., 2014). Methods of statistical analysis of images, that use biospeckle, are being developed, which allow for multidirectional application of the phenomenon of dynamic specular patterns as well as for biological materials (Adamiak et al., 2011).

Fruit producers often face a dilemma when to harvest fruit. The most common sign of ripening is the colour of the skin of the fruit. Other indicators are the increase in fruit weight, change in fruit firmness, fruit detachment force from peduncle and increase in the extract value. Assessment of fruit maturity mostly involves the need to break the fruit and its destruction during the measurement. Therefore, growers are interested in nondestructive measurement methods that allow them to not interfere with further growth and maturation of the fruit. The most important practical goal is the possibility to evaluate the physical characteristics of the fruit in order to assess its harvesting ripeness. Thanks to the selection of the most indicative factors, we are able to focus on a low number of parameters, which unveil the highest correlation.

\section{MATERIALS AND METHODS}

The research was carried out at the Horticulture Department and Department of Multimedia Systems of the West Pomeranian University of Technology in Szczecin. The experiment had place at a commercial orchard in area placed close to Szczecin. Cherry trees of Burlat cultivar were planted in the spacing of $3.5 \times 4.0 \mathrm{~m}$ in the podzolic soil of the VI valuation class.

In the fresh fruits, physical features (firmness, puncture of the skin) and soluble solids were measured. Firmness and puncture resistance of the skin was checked with a FirmTech2 apparatus (BioWorks, USA).

The result was expressed as a gram-force causing fruit surface to bend $1 \mathrm{~mm}$. Punctures were made with a stamp with a diameter of $3 \mathrm{~mm}$ (Ochmian et al., 2019). The fruit mass was measured with RADWAG WPX 4500 electronic scales $(0.1 \mathrm{~g}$ accuracy). Soluble solids (extract) content was determined with a PAL1 Konica Minolta refractometer. Fruit colour was measured with spectrophotometer Konica Minolta CM-700d. Measurements were conducted in CIE SCI/SCE $\mathrm{L}^{*} \mathrm{a} * \mathrm{~b}^{*}$ system - the full nomenclature is 1976 CIE $\mathrm{L} * \mathrm{a} * \mathrm{~b} *$ Space, International Commission on Illumination in Vienna ( $\mathrm{L}^{*}$ white $(100)$ black $(0)$, $a^{*}$ green $(-100)$ red $(+100), b^{*}$ blue $(-100)$ yellow
(+100)) (Hunterlab, 2012) (Nowakowska et al., 2017), through a $10^{\circ}$ observer type and D65 illuminant. The diameter of measuring aperture was $3 \mathrm{~mm}$. The measurements were made on all fruits covered by the experiment.

The dimensionality reduction uses the Principal Component Analysis implemented in MATLAB environment. It consists of the following steps:

1. input is the feature vector of 39 elements with spectral coefficients for each object (fruit) 2. calculate the mean vector over the whole set

3. normalize the set by subtracting the mean value calculated in step 2 from each object

4. calculate the covariance matrix for all objects

5. perform an eigen decomposition on the covariance matrix, resulting in two matrices of eigenvectors and eigenvalues, respectively

6 . based on the amplitude of eigenvalues, select 5 the most important eigenvectors

7. perform the dimensionality reduction on all objects in the set by multiplying them by a transformation matrix consisting of the selected eigenvectors

8. output objects with reduced dimensionality ( 5 elements per object vs original 39).

The correlation statistical analyses were performed using the Statistica 12.5 software (Statsoft, Poland). 


\section{RESULTS AND DISCUSSION}

The initial analysis of cross-correlation shows, that there is no direct and strong association between analysed physical parameters of fruits. The detailed cross-correlation values calculated for all possible pairs are presented below.

As can be seen, the weight and firmness negatively correlate, which is intuitively predictable (Tab. 1). Slightly weaker relations join weight and extract, firmness and puncture. It means, that it would be possible to find a correlation between each of the above-mentioned

parameters and a visual appearance of the fruit. Such visual appearance can be described by colour or, more precisely, by a spectrum of the light reflected by its surface.

In order to find a relation between above physical parameters of the fruits and the parameters derived from the analysis of light spectrum we performed a set of experiments involving several contemporary artificial intelligence methods. We selected certain classifiers in order to model a prediction scheme, which works in the following manner. We analyse a colour of the fruit (or the light spectrum) using a dedicated device. Then we predict certain physical parameters of the fruit-based on a previously learned classifier. The input parameters are: 39 component light spectrum in a range $360 \mathrm{mn}-740$ $\mathrm{mn}$ (divided into $10 \mathrm{mn}$ intervals), reduced light spectrum using Principal Component Analysis (5 dominant components were used), SCI L*a*b* and SCE $\mathrm{L}^{*} \mathrm{a} \mathrm{b}^{*}$ triples. The motivation for using direct light spectrum is obvious. It captures the whole information and it was used as a basis for further comparisons. The SCI/SCE L*a*b* colour components are taken from the device and are easy to acquire. One of our contributions is the idea of reducing the whole spectrum to the lowdimensional vector in order to decrease the comparison costs and to increase the generalization power. The PCA and derived methods were used at this stage since they have proved many times their effectiveness in similar tasks (Forczmański, 2016; Forczmański and Maleika, 2015; Forczmański and Frejlichowski, 2012). In order to perform classification, we employed a rough quantization of the output physical parameters (weight, firmness, puncture, fruit detachment force from peduncle), performed with the help of an expert. The quantization ranges are associated with preferred fruit characteristics. The details are presented in Table 2.

Table 1. The cross-correlation between pairs of fruit characteristics

\begin{tabular}{|c|c|c|c|c|c|}
\hline & weight & firmness & puncture & $\begin{array}{c}\text { fruit detachment } \\
\text { force from } \\
\text { peduncle }\end{array}$ & extract \\
\hline weight & 1.000 & -0.586 & -0.295 & 0.045 & 0.376 \\
firmness & -0.586 & 1.000 & 0.435 & 0.074 & -0.149 \\
puncture & -0.295 & 0.435 & 1.000 & 0.008 & 0.011 \\
$\begin{array}{c}\text { fruit detachment force } \\
\text { from peduncle }\end{array}$ & 0.045 & 0.074 & 0.008 & 1.000 & 0.115 \\
extract & 0.376 & -0.149 & 0.011 & 0.115 & 1.000 \\
\hline
\end{tabular}

Table 2. The intervals related to the particular classes (based on expert's suggestions)

\begin{tabular}{|c|c|c|c|}
\hline & Class 1 & Class 2 & Class 3 \\
\hline weight - p1 & $\mathrm{p} 1<=6$ & $6<\mathrm{p} 1<=9$ & $\mathrm{p} 1>9$ \\
firmness - p2 & $\mathrm{p} 2<=300$ & $300<\mathrm{p} 2<=500$ & $\mathrm{p} 2>500$ \\
puncture - p3 & $\mathrm{p} 3<=100$ & $100<\mathrm{p} 3<=180$ & $\mathrm{p} 3>180$ \\
fruit detachment force from peduncle - p4 & $\mathrm{p} 4<=200$ & $200<\mathrm{p} 4<=350$ & $\mathrm{p} 4>350$ \\
extract - p5 & $\mathrm{p} 5<=10$ & $10<\mathrm{p} 5<=15$ & $\mathrm{p} 5>15$ \\
\hline
\end{tabular}


Table 3. The distribution of fruits (single instances) belonging to the particular classes

\begin{tabular}{|c|c|c|c|}
\hline & Class 1 & Class 2 & Class 3 \\
\hline weight & 89 & 384 & 133 \\
firmness & 160 & 341 & 18 \\
puncture & 243 & 345 & 138 \\
fruit detachment force from \\
peduncle
\end{tabular}

The optimal number of Principal Components (PCs) was selected by means of a typical energetic criterion. The distribution of the energy carried by subsequent PCs are presented in Figure 1. As it can be seen, it is sufficient to represent the data with only 5 components while retaining the highest accuracy.

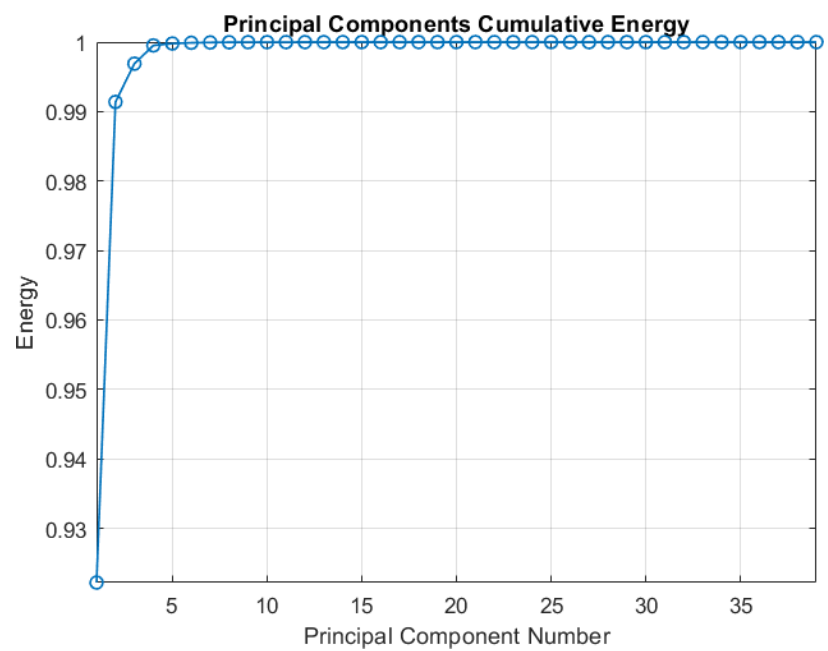

Figure 1. Visualization of Principal Components energetic distribution

The learning stage involved a typical 10-fold cross-validation scheme in order to reduce the influence of (un) fortunate learning/testing set selection. In other words, cross-validation is used to accurately evaluate a predictive model in practice.

Our dataset (physical parameters of the fruits associated with light spectrum and CIE SCI/SCE $\mathrm{L} * \mathrm{a} * \mathrm{~b} *$ colour parameters) is divided into two separate subsets. The first one is a training subset and contains objects that are used for creating a classification model. The second one is a testing subset and it is used for evaluation the quality of the classification. In order to increase the objectivity of the results, we divided the whole subset into partitions and used 10-fold (10 rounds) cross-validation approach. The results are then averaged over the rounds. In each round of crossvalidation we partition the dataset into complementary subsets, perform the training on a single subset and validate the model on the remaining subsets. At the classification stage we employed 8 well-known classification methods, namely Naïve Bayes Classifier (nbc), Support Vector Machine with linear kernel (svm-lin), Support Vector Machine with RBF kernel (svnrbf), Multi-Layer Perceptron (mlp), Nearest Neigghbour Classifier (1nn), Random Forest (rforest), Random Tree (rtree) and CART Classifier (cart). The classification was performed using WEKA data-mining software (Hall et al., 2009), while the Principal Component Analysis was performed using our own software developed in MATLAB environment.

The quality of the model is often expressed as classification accuracy. We evaluate it using True Positive and False Positive rates, where the first one counts of objects that were classified correctly in comparison to the all tested objects, while the latter counts objects that were misclassified, respectively. These rates are averaged over all classes. The results (in percent) are provided in Tables below (3-8). All the TP and FP rates are weighted according to the class size (provided below). The total number of objects in the set is equal to 606. The number of objects in class 2 is significantly higher than in other two classes since it represents fruits of required quality (which was mostly represented in the benchmark dataset). The best results are written in bold, having in mind that for two or more methods with the highest True Positive Rate, the lowest False Positive rate is taken into consideration. As can be seen, only the extract prediction is promising (almost $80 \%$ accuracy with less than $20 \%$ of false predictions). In this case PCA-based spectrum reduction and a linear SVM were employed. In other cases, the prediction accuracy is lower and fluctuate around $60 \%$. One interesting observation is that in those cases Multilayer Perceptron and PCA are the best (except fruit detachment force from peduncle, where MLP and direct SCE L*a*b* are the best). 
Table 4. The prediction accuracy (in terms of True Positive and False Positive factors) for extract evaluation based on various colour components

\begin{tabular}{|c|c|c|c|c|c|c|c|c|c|c|c|c|c|c|c|c|}
\hline Colour data & \multicolumn{2}{|c|}{ nbc } & \multicolumn{2}{c|}{ Svm-lin } & \multicolumn{2}{c|}{ Svm-rbf } & \multicolumn{2}{c|}{ mlp } & \multicolumn{2}{c|}{$1 \mathrm{nn}$} & \multicolumn{2}{c|}{ rforest } & \multicolumn{2}{c|}{ rtree } & \multicolumn{2}{c|}{ cart } \\
\hline & $\mathrm{tp}$ & $\mathrm{fp}$ & $\mathrm{tp}$ & $\mathrm{fp}$ & $\mathrm{tp}$ & $\mathrm{fp}$ & $\mathrm{tp}$ & $\mathrm{fp}$ & $\mathrm{tp}$ & $\mathrm{fp}$ & $\mathrm{tp}$ & $\mathrm{fp}$ & $\mathrm{tp}$ & $\mathrm{fp}$ & $\mathrm{tp}$ & $\mathrm{fp}$ \\
\hline $\begin{array}{c}\text { Spectrum } \\
\text { (39 comp) }\end{array}$ & 67.2 & 21.8 & $\mathbf{7 8 . 5}$ & 19.6 & 76.7 & 22.3 & 73.6 & 25.3 & 68.5 & 27.6 & 74.4 & 23.4 & 69.1 & 26.5 & 75.1 & 22.6 \\
Pca 5 components & 76.9 & 22.7 & $\mathbf{7 9 . 0}$ & $\mathbf{1 9 . 8}$ & 73.6 & 27.7 & 77.6 & 19.3 & 66.3 & 29.9 & 70.0 & 28.5 & 64.9 & 31.4 & 73.9 & 23.1 \\
SCI CIE L*a*b* & 71.9 & 21.3 & $\mathbf{7 5 . 9}$ & 23.3 & 73.9 & 25.4 & 74.3 & 24.7 & 69.5 & 29.2 & 72.6 & 26.2 & 68.6 & 29.6 & 72.8 & 26.5 \\
SCE CIE L*a*b* & 73.4 & 21.2 & 74.4 & 24.6 & 73.6 & 25.7 & 74.1 & 24.9 & 65.8 & 32.1 & 73.4 & 25.4 & 65.0 & 33.1 & 74.4 & 24.7 \\
\hline
\end{tabular}

Table 5. The prediction accuracy (in terms of True Positive and False Positive factors) for weight evaluation based on various colour components

\begin{tabular}{|c|c|c|c|c|c|c|c|c|c|c|c|c|c|c|c|c|}
\hline Colour data & \multicolumn{2}{|c|}{ nbc } & \multicolumn{2}{c|}{ Svm-lin } & \multicolumn{2}{c|}{ Svm-rbf } & \multicolumn{2}{|c|}{$\mathrm{mlp}$} & \multicolumn{2}{|c|}{$1 \mathrm{nn}$} & \multicolumn{2}{|c|}{ rforest } & \multicolumn{2}{|c|}{ rtree } & \multicolumn{2}{c|}{ cart } \\
\hline & $\mathrm{tp}$ & $\mathrm{fp}$ & $\mathrm{tp}$ & $\mathrm{fp}$ & $\mathrm{tp}$ & $\mathrm{fp}$ & $\mathrm{tp}$ & $\mathrm{fp}$ & $\mathrm{tp}$ & $\mathrm{fp}$ & $\mathrm{tp}$ & $\mathrm{fp}$ & $\mathrm{tp}$ & $\mathrm{Fp}$ & $\mathrm{tp}$ & $\mathrm{fp}$ \\
\hline $\begin{array}{c}\text { Spectrum } \\
\text { (39 comp) }\end{array}$ & 38.0 & 25.9 & 62.9 & 63.5 & 62.4 & 58.2 & 62.0 & 51.9 & 52.0 & 45.0 & 53.8 & 51.7 & 49.2 & 47.9 & 63.4 & 63.4 \\
Pca 5 components & 60.4 & 56.5 & 63.4 & 63.4 & 61.4 & 59.7 & $\mathbf{6 3 . 0}$ & $\mathbf{5 6 . 2}$ & 52.1 & 43.7 & 56.6 & 48.7 & 51.8 & 41.0 & 63.2 & 62.5 \\
SCI CIE L*a*b* & 47.2 & 37.9 & 63.4 & 63.4 & 62.0 & 58.2 & 61.7 & 62.7 & 53.0 & 43.0 & 58.7 & 45.3 & 52.5 & 44.2 & 63.4 & 63.4 \\
SCE CIE L*a*b* & 57.6 & 46 & 63.4 & 63.4 & 64.2 & 54.0 & 62.2 & 62.1 & 55.8 & 43.1 & 58.9 & 45.1 & 53.5 & 44.0 & 62.9 & 62.9 \\
\hline
\end{tabular}

Table 6. The prediction accuracy (in terms of True Positive and False Positive factors) for firmness evaluation based on various colour components

\begin{tabular}{|c|c|c|c|c|c|c|c|c|c|c|c|c|c|c|c|c|}
\hline Colour data & \multicolumn{2}{|c|}{ nbc } & \multicolumn{2}{c|}{ Svm-lin } & \multicolumn{2}{c|}{ Svm-rbf } & \multicolumn{2}{c|}{$\mathrm{mlp}$} & \multicolumn{2}{|c|}{$1 \mathrm{nn}$} & \multicolumn{2}{c|}{ rforest } & \multicolumn{2}{c|}{ rtree } & \multicolumn{2}{c|}{ cart } \\
\hline & $\mathrm{tp}$ & $\mathrm{fp}$ & $\mathrm{tp}$ & $\mathrm{fp}$ & $\mathrm{tp}$ & $\mathrm{fp}$ & $\mathrm{tp}$ & $\mathrm{fp}$ & $\mathrm{tp}$ & $\mathrm{fp}$ & $\mathrm{tp}$ & $\mathrm{fp}$ & $\mathrm{tp}$ & $\mathrm{fp}$ & $\mathrm{tp}$ & $\mathrm{fp}$ \\
\hline $\begin{array}{c}\text { Spectrum } \\
\text { (39 comp) }\end{array}$ & 35.5 & 24.2 & 55.8 & 55.8 & 58.1 & 49.3 & 55.6 & 45.8 & 45 & 39.8 & 51.8 & 42.3 & 46.3 & 38.7 & 55.3 & 54.6 \\
Pca 5 components & 58.1 & 45.8 & 55.8 & 56.3 & 56.4 & 50.9 & $\mathbf{5 6 . 6}$ & $\mathbf{4 5 . 9}$ & 43.9 & 39.1 & 52.3 & 42.6 & 43.7 & 41.8 & 56.9 & 51.3 \\
SCI CIE L*a*b* & 43.1 & 32.9 & 56.3 & 56.3 & 54.6 & 56.2 & 56.3 & 55.7 & 44.7 & 40.5 & 46.2 & 46.1 & 40.6 & 40.5 & 56.3 & 56.3 \\
SCE CIE L*a*b* & 45.2 & 37.8 & 56.3 & 56.3 & 56.1 & 51.7 & 56.1 & 56.0 & 43.9 & 41 & 46.7 & 43.7 & 45 & 42.9 & 56.3 & 56.3 \\
\hline
\end{tabular}

Table 7. The prediction accuracy (in terms of True Positive and False Positive factors) for puncture evaluation based on various colour components

\begin{tabular}{|c|c|c|c|c|c|c|c|c|c|c|c|c|c|c|c|c|}
\hline Colour data & \multicolumn{2}{|c|}{ nbc } & \multicolumn{2}{c|}{ Svm-lin } & \multicolumn{2}{c|}{ Svm-rbf } & \multicolumn{2}{c|}{$\mathrm{mlp}$} & \multicolumn{2}{|c|}{$1 \mathrm{nn}$} & \multicolumn{2}{c|}{ rforest } & \multicolumn{2}{|c|}{ rtree } & \multicolumn{2}{c|}{ cart } \\
\hline & $\mathrm{tp}$ & $\mathrm{fp}$ & $\mathrm{tp}$ & $\mathrm{fp}$ & $\mathrm{tp}$ & $\mathrm{fp}$ & $\mathrm{tp}$ & $\mathrm{fp}$ & $\mathrm{tp}$ & $\mathrm{fp}$ & $\mathrm{tp}$ & $\mathrm{fp}$ & $\mathrm{tp}$ & $\mathrm{fp}$ & $\mathrm{tp}$ & $\mathrm{fp}$ \\
\hline $\begin{array}{c}\text { Spectrum } \\
\text { (39 comp) }\end{array}$ & 39.9 & 34.4 & 59.4 & 50.5 & 58.8 & 47.5 & 59.6 & 48.7 & 46.5 & 50.9 & 49.8 & 48.5 & 47.0 & 48.7 & 57.4 & 50.6 \\
Pca 5 components & 53.8 & 41.6 & 57.6 & 53.7 & 55.9 & 50.7 & $\mathbf{5 9 . 6}$ & $\mathbf{4 8 . 6}$ & 49.2 & 48.6 & 53.8 & 44.8 & 53.6 & 43.4 & 61.1 & 43.7 \\
SCI CIE L*a*b* & 47.0 & 39.2 & 56.9 & 56.9 & 53.1 & 52.7 & 56.8 & 56.9 & 44.2 & 53.5 & 47.4 & 50.0 & 47.4 & 49.3 & 55.9 & 56.2 \\
SCE CIE L*a*b* & 48.8 & 43.3 & 56.9 & 56.9 & 56.3 & 53.4 & 56.4 & 57.1 & 51.3 & 47.0 & 49.0 & 49.2 & 48.0 & 48.4 & 57.1 & 56.0 \\
\hline
\end{tabular}


Table 8. The prediction accuracy (in terms of True Positive and False Positive factors) for fruit detachment force from peduncle evaluation based on various colour components

\begin{tabular}{|c|c|c|c|c|c|c|c|c|c|c|c|c|c|c|c|c|}
\hline Colour data & \multicolumn{2}{|c|}{ nbc } & \multicolumn{2}{|c|}{ Svm-lin } & \multicolumn{2}{c|}{ Svm-rbf } & \multicolumn{2}{|c|}{$\mathrm{mlp}$} & \multicolumn{2}{|c|}{$1 \mathrm{nn}$} & \multicolumn{2}{|c|}{ rforest } & \multicolumn{2}{|c|}{ rtree } & \multicolumn{2}{c|}{ cart } \\
\hline & $\mathrm{tp}$ & $\mathrm{fp}$ & $\mathrm{tp}$ & $\mathrm{fp}$ & $\mathrm{tp}$ & $\mathrm{fp}$ & $\mathrm{tp}$ & $\mathrm{fp}$ & $\mathrm{tp}$ & $\mathrm{fp}$ & $\mathrm{tp}$ & $\mathrm{fp}$ & $\mathrm{tp}$ & $\mathrm{fp}$ & $\mathrm{tp}$ & $\mathrm{fp}$ \\
\hline $\begin{array}{c}\text { Spectrum } \\
\text { (39 comp) }\end{array}$ & 34.2 & 30.2 & 52.6 & 52.6 & 50.2 & 52.5 & 47.9 & 49.7 & 38.8 & 38 & 40.3 & 43.4 & 39.1 & 37.5 & 52.6 & 52.6 \\
Pca 5 components & 51.3 & 49.5 & 52.6 & 52.6 & 48.3 & 49.7 & 51.5 & 51.7 & 37.5 & 37.3 & 43.7 & 43.1 & 37.5 & 38.5 & 52.5 & 52.7 \\
SCI L*a*b* & 50.7 & 49.1 & 52.6 & 52.6 & 51.2 & 51.1 & $\mathbf{5 2 . 6}$ & $\mathbf{5 0 . 1}$ & 38.8 & 39.2 & 39.1 & 43.6 & 39.4 & 39.7 & 52.6 & 52.6 \\
SCE L*a*b* & 51.8 & 49 & 52.6 & 52.6 & 50 & 50.4 & 52 & 51.7 & 35.5 & 42.1 & 41.3 & 40.4 & 40.4 & 37.8 & 52.6 & 52.6 \\
\hline
\end{tabular}

In order to confirm the optimal selection of PCs number, we performed also a set of experiments involving changing the number of PCs in range 139. As expected, the prediction accuracy was lower or very similar (yet for a higher number of PCs). Hence, five PCs were set as optimum.

To evaluate fruit quality, the procedure typical for many non-destructive methods based on the black box principle is applicated. At first, fruits are measured by non-destructive and conventional methods. Then, the data are processed by some of the many methods available in the domain of statistics and information technology to find a relationship between a conventional measure and the multiple responses of the non-destructive method.As shown by the aforementioned procedure, the confirmation of extract significance for the determination of fruit colours (optimum for the harvesting period) is given by the comparison of the coefficients of the correlation between the coordinates $\mathrm{Lab}$ and the extract, fruit mass, firmness, breakthrough strength and ability to tear off the fruit from the stem (Table 9). The closest negative correlations were recorded between the $\mathrm{Lab}$ and the extract.

No relationship was found between CIE colour parameters and fruit mass. Also no relationship was found between the parameter colour $a^{*} b^{*}$ and the force required to tear off the fruit from its stalk. The non-destructive mechanical methods are used mainly to measurements of firmness (Shmulevich, 2004). These methods use low-mass impact tests. The results of such tests are variable and very sensitive to changes of fruit positions, the impact angle and the deviation of the fruit from the spherical shape. The firmness of these fruits is highly dependent on water content. Nondestructive mechanical methods measure mostly the stiffness and resilient fruits properties. They are associated more with turgor, than as in the case of a penetrometer with the mechanical strength of cell walls (Hertog et al., 2004).

In the experiment conducted by Chełpiński (2007), the R.H.S. Colour Chart developed by the Royal Horticultural Society London (1966), was used. Due to the great diversity of colours, they were classified into three groups. The darkest fruits that are easily recognised as ripe (group A) had their skin in the colours designated (according to the scale) with numbers from 181 to 187 . It was found that more than $63 \%$ of the fruits, harvested within the period optimum for the Burlat species on the PHL A rootstocks, were within the colour range 187a-c, 185ab, 183ab, and 181a. The average extract value for the group was (14.87\%). In order to verify the value according to the CIE $\mathrm{L}^{*} \mathrm{a} * \mathrm{~b} *$ chart, a spectrophotometer measurement was taken (Tab. 10) by following the procedure provided in the publication by Voss (1992). This was the basis to find that the fruits of optimum ripeness, as suggested by the experience gained by Chełpiński (2007), featured the following parameters: L*22$37, a * 13-39, b^{*} 9-19$. The remaining fruit groups were within the range $L^{*} 33-83, a^{*} 5-51$ and $b^{*} 4-$ 54. Plotting lines of regression between the most colour-correlated property, i.e. the extract, and the colour parameters (Fig. 2) showed that coordinate values were $L^{*} 30-20, a^{*} 30-0, b^{*} 10-0$ for the extract range of $12-20 \%$. Among the evaluated colour coordinates $L^{*}, a^{*}, b^{*}$, changes of the skin colour in correlation with the extract were best reflected by values of the coordinate $a^{*}$. This is also confirmed in the application to measurements of the apple tree by Lysiak et al., (2012), whereas for anthocyanins Goncalves et al., (2007), the values of the coordinate $b^{*}$ were more significant. 
Table 9. Highlighting the different correlations between weight, firmness, puncture, fruit detachment force from peduncle, extract and colour parameters $\left(\mathrm{L}^{*}, \mathrm{a}^{*}, \mathrm{~b}^{*}\right)$ of ripe cherries Burat cultivar

\begin{tabular}{|c|c|c|c|}
\hline & $\mathrm{L}^{*}$ & $\mathrm{a}^{*}$ & $\mathrm{~b}^{*}$ \\
\hline weight & -0.028 & -0.024 & -0.025 \\
firmness & 0.281 & 0.338 & 0.322 \\
puncture & 0.157 & 0.189 & 0.192 \\
fruit detachment force & -0.094 & -0.079 & -0.078 \\
from peduncle & -0.657 & -0.723 & -0.693 \\
\hline
\end{tabular}

Table 10. Spectrophotomelrically measured coordinates of user-selected Royal Horticultural Society colour chart chips

\begin{tabular}{|c|c|c|c|}
\hline Number of colour & $\mathrm{L}^{*}$ & $\mathrm{a}^{*}$ & $\mathrm{~b}^{*}$ \\
\hline $187 \mathrm{~A}$ & 22.01 & 13.81 & 9.03 \\
$187 \mathrm{~B}$ & 26.26 & 26.30 & 11.70 \\
$187 \mathrm{C}$ & 30.10 & 31.76 & 10.65 \\
$185 \mathrm{~A}$ & 29.29 & 33.42 & 19.36 \\
$185 \mathrm{~B}$ & 35.92 & 38.05 & 12.82 \\
$183 \mathrm{~A}$ & 28.59 & 24.53 & 17.84 \\
$183 \mathrm{~B}$ & 30.84 & 26.81 & 15.82 \\
$181 \mathrm{~A}$ & 37.44 & 34.58 & 18.97 \\
\hline
\end{tabular}

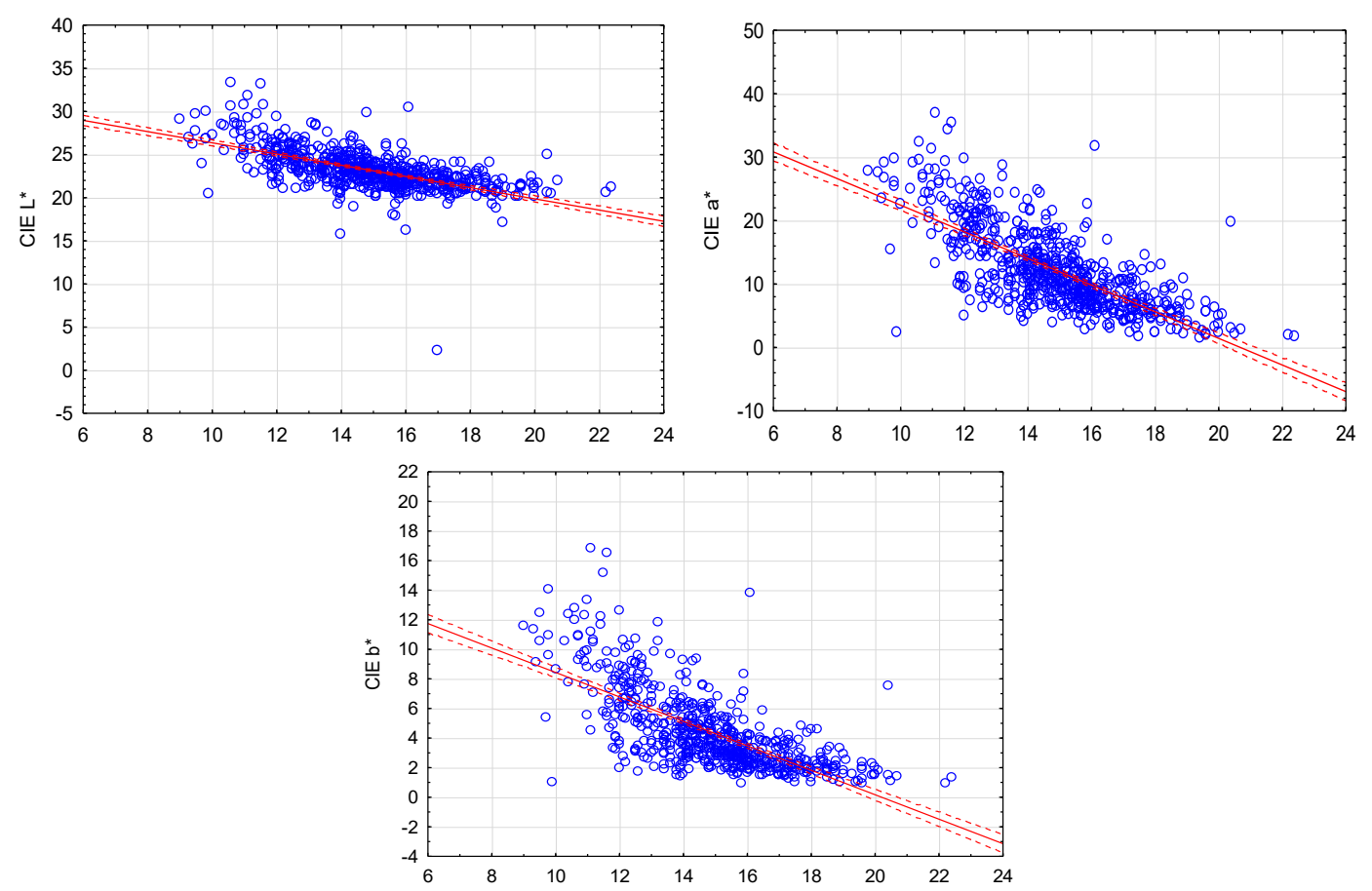

Figure 2. A simple regression showing the relationship between the value of the extract in the Burlat fruit and the coordinate value CIE L*, a*, b*

\section{CONCLUSIONS}

For the non-destructive evaluation of ripeness of the Burlat cherry on the PHL A rootstocks, the optimum colour measurement uses a spectrophotometer, because it is most strongly coupled with the extract measurement, which is sufficient to reflect the degree of fruit ripeness.
Changes of the fruits of sweet cherry skin colour were best reflected by values of the parameter *a. However, to determine the optimal value for determining a fruit set, all colour coordinates CIE $\mathrm{L} * \mathrm{a} * \mathrm{~b} *$ are important.

The best period for harvesting the Burlat cherry occurs if the coordinate $\mathrm{a}^{*}$ is within the range 30.0 to 0.0 , coordinate $\mathrm{b}^{*}$ within 10.0 and 0.0 and coordinate $\mathrm{L}^{*}$ within 30.0 to 20.0 . 


\section{REFERENCES}

1. Antal, T., Sikolya, L., \& Kerekes, B. (2013). Assessment of Freezing Pre-Treatments for the Freeze Dried of Apple Slices. Acta Universitatis Cibiniensis. Series E: Food Technology, 17(2), 3-14.

2. Adamiak, A., Zdunek, A., Kurenda, A., \& Kuczynski, A.P. (2011). Characteristics and application of biospeckle Phenomenon in the study of plant materials (a review). Acta Agrophysica, 18(2), 215-224.

3. Bauriegel, E., Giebel, A., \& Herppich, W.B. (2011). Hyperspectral and chlorophyll fluorescence imaging to analyse the impact of Fusarium culmorum on the photosynthetic integrity of infected wheat ears. Sensors, 11, 3765-3779. doi:10.3390/s110403765

4. Chełpiński, P. (2007). Wpływ wybranych podkładek na wzrost i plonowanie oraz skład chemiczny liści i owoców czereśni na Pomorzu Zachodnim. Wyd. Nauk. AR Szczecin ISSN 0239-6467.

5. Crisosto, C., Crisosto, G.M., \& Metheney, P. (2003). Consumer acceptance of 'Brooks' and 'Bing' cherries is mainly dependent on fruit SSC and visual skin color. Postharvest Biol Tec, 28, 159-167.

6. Escribano, S., Biasi, W.V., Lerud, R., Slaughter, D.C., \& Mitcham, E.J. (2017). Non-destructive prediction of soluble solids and dry matter content using NIR spectroscopy and its relationship with sensory quality in sweet cherries. Postharvest Biol. Tec, 128, 112-120. https://doi.org/10.1016/j.postharvbio.2017.01.016

7. Ferrer, A., Remon, S., \& Negueruela, A.I. (2005). Changes during ripening of the very late season Spanish peach cultivar Calanda Feasibility of using CIELab coordinates as maturity indices. Sci Hort, 105, 435-446. https://doi.org/10.1016/j.scienta.2005.02.002

8. Forczmański, P., \& Frejlichowski, D. (2012). Classification of elementary stamp shapes by means of reduced point distance histogram representation. Proceedings Machine Learning and Data Mining MLDM 2012, Lecture Notes in Artificial Intelligence, 7376, 603-616. https://doi.org/10.1007/978-3642-31537-4_47

9. Forczmański, P., \& Maleika, W. (2015). Near-lossless PCA-based Compression of Seabed Surface with Prediction. Proceedings 12th International Conference on Image Analysis and Recognition ICIAR 2015, Lecture Notes in Computer Science, 9164, 119-128. https://doi.org/10.1007/978-3-319-20801-5_13

10. Forczmański, P. (2016). Evaluation of Singer's Voice Quality by Means of Visual Pattern Recognition. J Voice, 30(1), 127.e21-127.e30

11. Goncalves, B., Silva, A.P., Moutinho-Pereira, J., Bacelar, E., Rosa, E., \& Meyer, A.S. (2007). Effect of ripeness and postharvest storage on the evolution of colour and anthocyanins in cherries (Prunus avium L.). Food Chem, 103: 976-984. doi:10.1016/j.foodchem.2006.08.039

12. Hall, M., Frank, E., Holmes, G., Pfahringer, B., Reutemann, P., \& Witten, I.H. (2009). The WEKA data mining software: an update. ACM SIGKDD explorations newsletter, 11(1), 10-18.

13. Hertog, M.L., Ben-Arie, R., Róth, E., \& Nicolaï, B.M. (2004). Humidity and temperature effects on invasive and non-invasive firmness measures. Postharvest Biol Tec, 33(1), 79-91. https://doi.org/10.1016/j.postharvbio.2004.01.005

14. Hunterlab. (2012). Measuring Color using Hunter L, a, b versus CIE 1976 L*a*b*. AN 1005.00: 1-4. (www.hunterlab.com/an-1005b.pdf).

15. Li, X., Wei, Y., Xu, J., Feng, X., Wu, F., Zhou, R., \& He, Y. (2018). SSC and pH for sweet assessment and maturity classification of harvested cherry fruit based on NIR hyperspectral imaging technology. Postharvest Biol. Tec, 143, 112-118. https://doi.org/10.1016/j.postharvbio.2018.05.003

16. Łysiak, G., Kurlus, R., Zydlik, Z., \& Walkowiak-Tomczak, D. (2014). Apple skin colour changes during harvest as an indicator of maturity. Acta Sci Pol, Hortorum Cultus, 13(3), 71-83.

17. Łysiak, G. (2011). The determination of harvest index of 'Šampion' apples intended for long storage. Acta Sci Pol, Hortorum Cultus, 10(3), 273-282.

18. Łysiak, G. (2012). The base colour of fruit as an indicator of optimum harvest date for two apple cultivars (Malus domestica Borkh.). Folia Hort, 24(1), 81-89. doi:https://doi.org/10.2478/v10245-012$0012-2$

19. Mireei, S.A., Mohtasebi, S.S., Massudi, R., Refiee, S., \& Arabanian, A.S. (2010). Feasibility of near infrared spec-troscopy for analysis of date fruits. Int Agrophysics, 24, 351-356. 
20. Nicolai, B.M., Lamertyn, E.A., Veraverbeke, M.A., Hertog, T.M., Roth, E., Berna, A., Alamar, M.C., Verlinden, B., \& Jancsok, P. (2005). Non-destructive techniques for measuring quality of fruit and vegetables. Acta Hortic, 682, 1333-1339.

21. Nowakowska, M., Ochmian, I., \& Mijowska, K. (2017). Assessment of the sea buckthorn growing in urban conditions-the quality of berries and leaves. $J$ Elem, 22(2), 399-409. doi:10.5601/jelem.2016.21.2.1168

22. Overbeck, V., Schmitz, M., \& Blanke, M. (2017). Non-Destructive Sensor-Based Prediction of Maturity and Optimum Harvest Date of Sweet Cherry Fruit. Sensors, 17(2), 277.

23. Ochmian, I., Oszmiański, J., Lachowicz, S., \& Krupa-Małkiewicz, M. (2019). Rootstock effect on physico-chemical properties and content of bioactive compounds of four cultivars Cornelian cherry fruits. Scientia Horticulturae, 256, 108588.

24. Ochmian, I., Yordanov, A., Mijowska, K., \& Chełpiński, P. (2016). Effect of storing Persimmon (Diospyros kaki) fruits under shelf life conditions on selected physical parameters and chemical composition. Food Science Technology Quality, 1(104), 155-166. DOI: 10.15193/zntj/2016/104/109

25. Overbeck, V., Schmitz, M., \& Blanke, M. (2017). Non-Destructive Sensor-Based Prediction of Maturity and Optimum Harvest Date of Sweet Cherry Fruit. Sensors, 17(2), 277.

26. Pappas, C.S., Takidelli, C., Tsantili, E., Tarantilis, P.A., \& Polissiou, M.G. (2011). Quantitative determination of anthocyanins in three sweet cherry varieties using diffuse reflectance infrared Fourier transform spectroscopy. J Food Compos Anal, 24(1), 17-21. https://doi.org/10.1016/j.jfca.2010.07.001

27. Paz, P., Sánchez, M.T., Pérez-Marín, D., Guerrero, J.E., \& Garrido-Varo, A. (2008). Nondestructive determination of total soluble solid content and firmness in plums using near-infrared reflectance spectroscopy. J Agric Food Chem, 56(8), 2565-2570. doi:10.1021/jf073369h

28. Peng, Y., \& Lu, R.. (2008). Analysis of spatially resolved hyperspectral scattering images for assessing apple fruit firmness and soluble solids content. Postharvest Biol Technol, 48, 52-62. doi:10.1016/j.postharvbio.2007.09.019

29. Royal Horticultural Society. (2007). Royal Horticultural Society colour chart. Royal Hort. Soc., London

30. Rutkowski, K.P., Michalczuk, B., \& Konopacki, P. (2008). Nondestructive determination of 'Golden Delicious' apple quality and harvest maturity. J Fruit Ornam Plant Res, 16, 39-52.

31. Seifert, B., Zude, M., Spinelli, L., \& Torricelli, A. (2015). Optical properties of developing pip and stone fruit reveal underlying structural changes. Physiol Plantarum, 153(2), 327-336. https://doi.org/10.1111/ppl.12232

32. Serrano, M., Diaz-Mula, H.M., Zapata, P.J., Castillo, S., Guillen, F., Martinez-Romero, D., Valverde, J.M., \& Valero, D. (2009). Maturity stage at harvest determines the fruit quality and antioxidant potential after storage of sweet cherry cultivars. $J$ Agric Food Chem, 57, 3240-3246. doi:10.1021/jf803949k

33. Shmulevich, I. (2004). Mechanical techniques for non-destructive sorting of agricultural products. $I$ Georgofili. Quaderni 2004 -III, 33-53.

34. Voss, D.H. (1992). Relating Colorimeter Measurment of Plant Color to the Royal Horticultural Society Colour Chart. HortSci, 27(12), 1256-1260.

35. Yusufe, M., Mohammed, A., \& Satheesh, N. (2017). Effect of duration and drying temperature on characteristics of dried tomato (Lycopersicon esculentum L.) cochoro variety. Acta Universitatis Cibiniensis. Series E: Food Technology, 21(1), 41-50.

36. Zanella, A., Vanoli, M., Rizzolo, A., Grassi, M., Eccher Zerbini, P., Cubeddu, R., \& Spinelli, L. (2012). Correlating optical maturity indices and firmness in stored 'Braeburn' and' Cripps Pink' apples. In VII International Postharvest Symposium. 1012 pp. 1173-1180.

37. Zerbini, P.E., Grassi, M., Cubeddu, R., Pifferi, A., \& Torricelli, A. (2003). Time-resolved reflectance spectroscopy can detect internal defects in pears. Acta Hort, 599, 359-365.

38. Zerbini, P.E. (2006). Emerging technologies for non-destructive quality evaluation of fruit. $J$ Fruit Ornam Plant Res, 14(Suppl. 2), 13-23.

39. Zude, M., Pflanz, M., Spinelli, L., Dosche, C., \& Torricelli, A. (2011). Non-destructive analysis of anthocyanins in cherries by means of Lambert-Beer and multivariate regression based on spectroscopy 
and scatter cor-rection using time-resolved analysis. $J$ Food Eng, 103(1), 68-75. doi:10.1016/j.jfoodeng.2010.09.021

40. Zude, M., Sasse, J., \& Schallnus, H. (2009). Non-Invasive Sensing of Fruit Development in Banana and Papaya by Means of a Spectroscopic Approach. International Symposium Postharvest Pacifica 2009Pathways to Quality: V International Symposium on Managing Quality in 880, 2009, November, pp. 277-281. doi:10.17660/ActaHortic.2010.880.32 